\title{
Effects of Electromagnetic Field Use on J aw Bone Densification
}

\begin{abstract}
EDWIN SEVER BECHIR ${ }^{1}$, FARAH BECHIR ${ }^{2 *}$, BOGDAN VLADILA ${ }^{2}$
IUniversity of Medicine and Pharmacy of Tirgu Mures, Faculty of Dentistry, 38 Gheorghe Marinescu Str., 540142, Tirgu Mures, Romania

2Electronic Doctor SRL Nice, 5A J ean Monnet Str., 011955, Bucharest, Romania

The working hypothesis started from the premise of the benefits of the electromagnetic field therapy(EMFT) benefits in order to densify the periodontal bone tissues. The objective of this study was to quantify the results of using this therapy with the Electronic Doctor Stem Generator (EDSG) in the densification of affected alveolar bone tissues by clinical and radiological examinations. The study was performed on 30 patients, who benefited from adjuvant therapy in the electromagnetic field (EMF) with the EDSG device after performing the specific dental treatments. We applied these very low-frequency EMF bioactivation treatment delivered by EDSG device, 30 daily exposures for a 2-hour interval. The results proved the appreciable reduction of teeth mobility, the reduction of periodontal pockets depth and the bone regeneration in the regions exposed to the EMF produced by EDSG device. EMF adjuvant therapy with EDSG device is an innovative, atraumatic and non-invasive therapy.
\end{abstract}

\section{Keywords: medical device, periodontal lesions, EMFT, healing}

The (EMF) is the assembly of the electric and magnetic fields, which oscillate and generate each other when the electric current passes through a conductor [1]. In medicine, electromagnetic field therapy (EMFT) was implemented by Robert Becker, who used external electromagnetic fields to induce bone growth by increasing the rate of biochemical reactions, cell division and healing acceleration [2]. The effects of EMFTs on human health are presented in figure 1 .

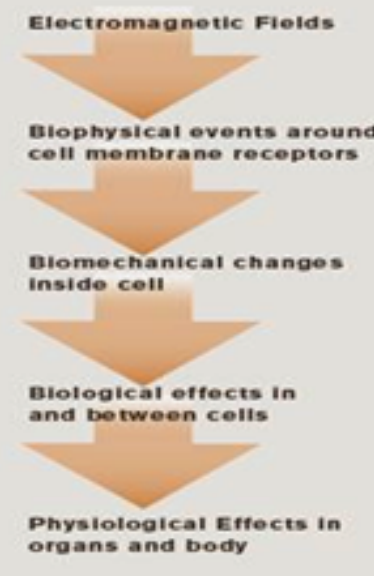

Fig. 1. Effects of EMFs on Human Health [3]

Electronic Doctor Stem Generator (EDSG) is a patented medical device, approved by the Romanian Ministry of Health and certified by the European Union. This device consists of an extraoral and an intraoral part. EMF inductors are disposed in an intraoral applicator located on the inner surface of a thermoformed mouthguard (fig. 2).

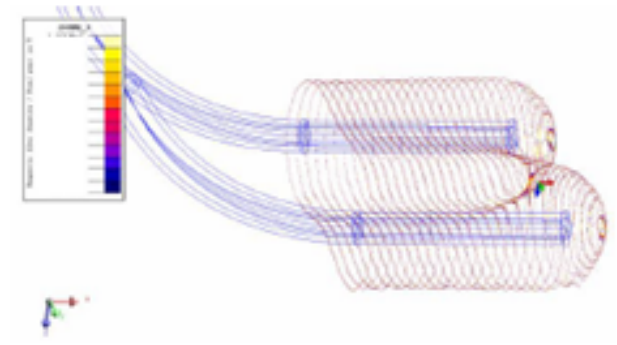

Fig. 2. Electromagnetic contour lines on the surface of the action area of the applicator
The electric generator and the coil system, approved with the CE mark in class 2a, generate an electromagnetic field. The duration of the emission and the electromagnetic characteristics of this device are controlled by a custom software embedded in the extraoral component of the device, which also includes the number of sessions and operating time settings. The coil system is placed and immobilized on a personalized thermoformed mouthguard for each patient, and is partiallylined with silicone material [4]. The applicator acts on the entire dental arch.

The working hypothesis started from the premise of the benefits of the EMFT benefits in order to densify the periodontal bone tissues.

The objective of this study was to quantify the results of using this therapy with the EDSG in the densification of affected alveolar bone tissues by clinical and radiological examinations.

\section{Experimental part}

Material and methods

The study was approved by the Ethics Commission of the University of Medicine and Pharmacy of Tirgu Mures. All patients enrolled in the study agreed to the treatment plan and signed the informed consent form for participation in the research.

In order to perform the study, 30 patients, 14 women and 16 men, aged 36-60 years old (mean age 48 years, \pm 12 years), who benefited from adjuvant therapy in the electromagnetic field with the electronic device EDSG after performing specific dental treatments.

The patients selected for study were divided into two groups:

- The first group of patients / group I received adjuvant therapy with EDSG (15 patients, 7 women and 8 men);

- Group II / control - patients who did not perform EMF therapy (15 patients, 7 women and 8 men).

Chart 1 shows the distribution of patients by gender and by age in the two studied groups.

Inclusion criteria in this study:

- patients aged 30-60 years old, with I and II degree of dental mobility and / or gingival retraction / bone resorption, affecting the root furcation;

- patients requiring complex oral rehabilitation, including prosthetic restorations. 

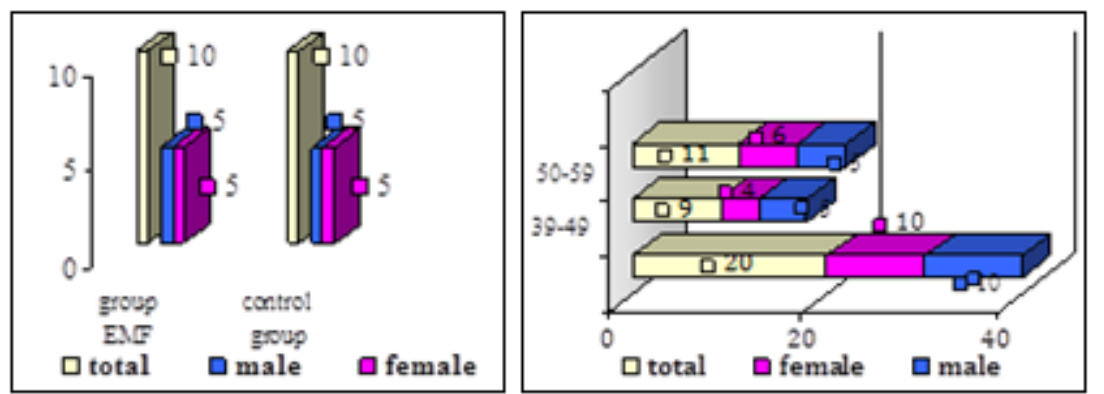

Chart 1. Distribution of patients by gender and by age in the two studied groups:left: batch I

(EDSG); right: batch II (control)

Exclusion criteria in this study:

- patients with atypical gingival proliferation, tongue and soft tissue hyperplasia, benign intraoral tumours, metastases / surgeries, or with a history of oncology;

- pregnant patients;

- people with pacemakers or other devices that control body functions.

The clinical protocol applied to all patients included in the study of the effects of EMF adjuvant therapy with the EDSG was:

- Specialized consultation and x-rays;

- Diagnosis of general health status, oral cavity and periodontal tissues, dental and periodontal status, determination of Oral Hygiene Index = $\mathrm{OHI}$;

- Establishment of the treatment plan, signing of the informed consent;

- Patient training on artificial hygiene procedures, carrying out professional hygiene;

- Performing specific interventions of dentistry, according to the established treatment plan and the existing conditions;

- Applying a very low-frequency EMF bioactivation treatment delivered by EDSG device, 30 daily exposures for a 2-hour interval (the patients participating in this study were practically trained on how to apply the mouthguard on the dental arches, how to clean the tray, how to connect and use the device, and details referring to the number of exposure sessions.

- Clinical evaluation on the 30th day after the last use of the EDSG device, or whenever necessary;

- Patientmonitoring was performed by 3 periodic control recalls, with a frequency of 2 months.

Figure 3 shows the appearance of the EDSG device, ready for use.

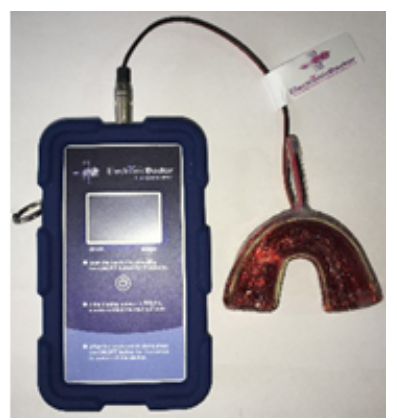

Fig. 3. Electronic Doctor Stem Generator (EDSG) device, ready for use

\section{Results and discussions}

Of the patients treated according to the clinical protocol described above, we present a case.

Patient M.E. aged 54, came to the office for dental treatments in J une 2016. The anamnesis revealed that the patient lost her upper frontal teeth due to pathological mobility. At the clinical examination, we found increased bone resorption with generalized dental plaque, extended pathological mobility in all teeth of dental arches, and occlusal interferences. The patient denied the existence of any chronic disease. We have carried out professional

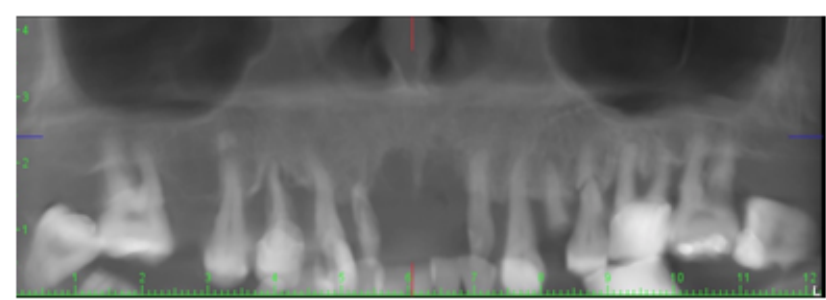

Fig. 4. Initial OPG in the upper jaw

scaling and hygiene, insisted on the need for proper oral hygiene by the patient. We indicated the use of OPG, but due to the deficient bone loss, we also indicated maxillary and mandibular CBCT. When examining the CBCT sections, the existence of profound marginal periodontitis at the level of all jaw and mandibular arches was revealed. In figure 4 the OPG of the upper arch is presented at the beginning of treatment.

Dental treatment was performed according to the above protocol and consisted in the extraction of irrecoverable periodontal teeth, scaling/root planning and devitalisation of the remaining teeth, and later, the preparation of the abutment teeth for two bridges of zirconium (because zirconium has a specific low weight) covered with ceramic layer. We did not include molars 1.7, 2.8, 3.7 in the fixed restorations because of their mobility (grade II to III), but we also wanted to observe the effects of EMF on these molars. The restorations were inserted onto the dental arches after completion of EMF therapy, but prior to the next CBCT examination. EMC therapy was performed according to protocol, for 30 days for 2 hours for each dental arch, after the completion of dental treatments. In figure 5 is presented a section of the final CBCT in the maxillary arch, performed 30 days after the completion of EMF therapy.

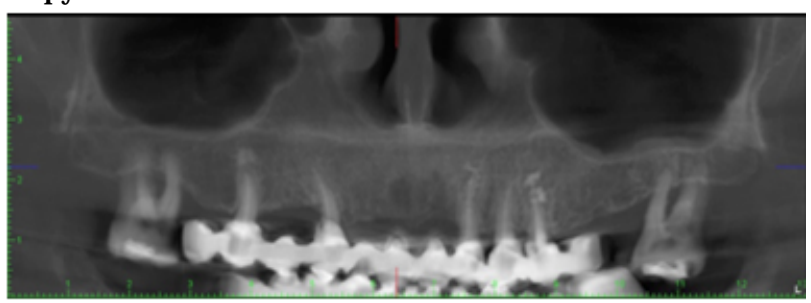

Fig. 5. CBCT section of the maxillary arch 30 days after the completion of EMF therapy

Sections of the right maxillary hemiarch CBCT can be seen below: figure6 shows the initial CBCT that was performed at the patient presentation, and in fig. 7 final CBCT after completion of dental treatment and 30 days after completion of EMC therapy.

In figure 8 the clinical images at the presentation of the patient (fig. 8A) and 30 days after completion of CEM therapy are shown (fig. 8B).

Two months after the start of treatment, the results of intraoral and radiological examinations (by comparison of pre-treatment and post-treatment radiographs) were evaluated and shown that dental mobility and the depth of periodontal pockets were reduced and that bone density 

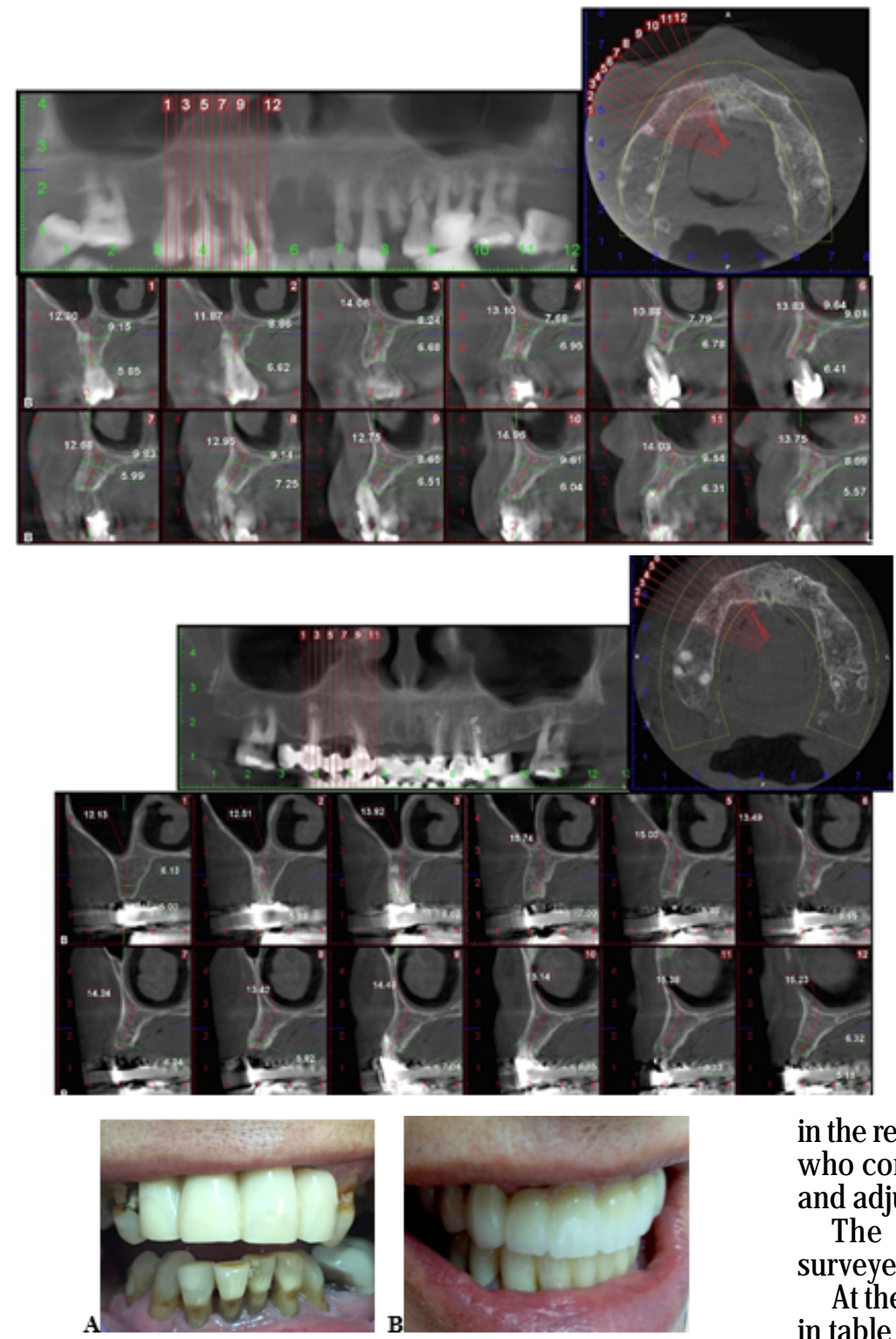

Fig. 8. Clinical picture of patient at presentation $(A)$; the final restorations inserted into the oral cavitv (B)

\begin{tabular}{|c|c|c|c|c|}
\hline & & & $\begin{array}{c}\text { Group IEMF } \\
15 \text { patients }\end{array}$ & $\begin{array}{c}\text { Group } \\
\text { II/Control } \\
15 \text { patients }\end{array}$ \\
\hline \multirow{12}{*}{$\begin{array}{c}\text { Clinical exam at } \\
\text { patient presentation }\end{array}$} & \multirow{4}{*}{$\begin{array}{l}\text { OHI } \\
\text { Index }\end{array}$} & 0 & - & - \\
\hline & & 1 & $8(=53,33 \%)$ & $8(=53,33 \%)$ \\
\hline & & 2 & $5(=33,33 \%)$ & $5(=33,33 \%)$ \\
\hline & & 3 & $2(=13,33 \%)$ & $2(=13,33 \%)$ \\
\hline & \multirow{4}{*}{$\begin{array}{l}\text { Dental } \\
\text { mobility }\end{array}$} & No mobility & - & - \\
\hline & & Gr. 1 & $7(=46,66 \%)$ & $7(=46,66 \%)$ \\
\hline & & Gr. 2 & $7(=46,66 \%)$ & $7(=46,66 \%)$ \\
\hline & & Gr. 3 & $1(=6,66 \%)$ & $1(=6,66 \%)$ \\
\hline & \multirow{4}{*}{$\begin{array}{l}\text { Periodo } \\
\text { ntal } \\
\text { pocket } \\
\text { depth }\end{array}$} & No pockets & - & - \\
\hline & & $0,5-1 \mathrm{~mm}$ & $7(=46,66 \%)$ & $7(=46,66 \%)$ \\
\hline & & $1-1,5 \mathrm{~mm}$ & $5(=33,33 \%)$ & $5(=33,33 \%)$ \\
\hline & & $1,5-2 \mathrm{~mm}$ & $3(=20 \%)$ & $3(=20 \%)$ \\
\hline \multirow{12}{*}{$\begin{array}{l}\text { Clinical exam at } 2 \\
\text { months after the end } \\
\text { of the treatment }\end{array}$} & \multirow{4}{*}{$\begin{array}{l}\text { OHI } \\
\text { Index }\end{array}$} & 0 & $11(=73,33 \%)$ & $10(=66,66 \%)$ \\
\hline & & 1 & $3(=20 \%)$ & $4(=26,66 \%)$ \\
\hline & & 2 & $1(=6,66 \%)$ & $1(=\sigma, 6 \sigma \%)$ \\
\hline & & 3 & - & - \\
\hline & \multirow{4}{*}{$\begin{array}{l}\text { Dental } \\
\text { mobility }\end{array}$} & No mobility & $6(=40 \%)$ & $5(=33,33 \%)$ \\
\hline & & Gr. 1 & $9(=60 \%)$ & $9(=60 \%)$ \\
\hline & & Gr. 2 & - & $1(=6,66 \%)$ \\
\hline & & Gr. 3 & - & - \\
\hline & \multirow{4}{*}{$\begin{array}{l}\text { Periodo } \\
\text { ntal } \\
\text { pocket } \\
\text { depth } \\
\end{array}$} & No pockets & $6(=40 \%)$ & $4(=26,66 \%)$ \\
\hline & & $0,5-1 \mathrm{~mm}$ & $8(=53,33 \%)$ & $8(=53,33 \%)$ \\
\hline & & $1-1,5 \mathrm{~mm}$ & $1(=6,66 \%)$ & $3(=20 \%)$ \\
\hline & & $1,5-2 \mathrm{~mm}$ & - & - \\
\hline
\end{tabular}

Table 1

COMPARATIVE RESULTS OBTAINED IN THE TWO STUDIED GROUPS 


\begin{tabular}{|c|c|c|c|c|}
\hline \multirow{12}{*}{$\begin{array}{c}\text { Clinical exam at } 4 \\
\text { months after the end } \\
\text { of the treatment }\end{array}$} & \multirow{4}{*}{$\begin{array}{c}\text { OHI } \\
\text { Index }\end{array}$} & 0 & $10(=66,66 \%)$ & $9(=60 \%)$ \\
\hline & & 1 & $4(=26,66 \%)$ & $5(=33,33 \%)$ \\
\hline & & 2 & $1(=6,66 \%)$ & $1(=6,66 \%)$ \\
\hline & & 3 & - & - \\
\hline & \multirow{4}{*}{$\begin{array}{c}\text { Dental } \\
\text { mobility }\end{array}$} & No mobility & $7(=46,66 \%)$ & $6(=40 \%)$ \\
\hline & & Gr. 1 & $8(=53,33 \%)$ & $7(=46,66 \%)$ \\
\hline & & Gr. 2 & - & $2(=13,33 \%)$ \\
\hline & & Gr.3 & - & - \\
\hline & \multirow{4}{*}{$\begin{array}{l}\text { Periodo } \\
\text { ntal } \\
\text { pocket } \\
\text { depth }\end{array}$} & No pockets & $6(=40 \%)$ & $5(=33,33 \%)$ \\
\hline & & $0,5-1 \mathrm{~mm}$ & $9(=60 \%)$ & $8(=53,33 \%)$ \\
\hline & & $1-1,5 \mathrm{~mm}$ & - & $2(=13,33 \%)$ \\
\hline & & $1,5-2 \mathrm{~mm}$ & - & - \\
\hline \multirow{12}{*}{$\begin{array}{l}\text { Clinical exam at } 6 \\
\text { months after the end } \\
\text { of the treatment }\end{array}$} & \multirow{4}{*}{$\begin{array}{c}\text { OHI } \\
\text { Index }\end{array}$} & 0 & $10(=66,66 \%)$ & $9(=60 \%)$ \\
\hline & & 1 & $4(=26,66 \%)$ & $5(=33,33 \%)$ \\
\hline & & 2 & $1(=6,66 \%)$ & $1(=6,66 \%)$ \\
\hline & & 3 & - & - \\
\hline & \multirow{4}{*}{$\begin{array}{c}\text { Dental } \\
\text { mobility }\end{array}$} & No mobility & $8(=53,33 \%)$ & $6(=40 \%)$ \\
\hline & & Gr. 1 & $7(=46,66 \%)$ & $8(=53,33 \%)$ \\
\hline & & Gr. 2 & - & $1(=6,66 \%)$ \\
\hline & & Gr.3 & - & - \\
\hline & \multirow{4}{*}{$\begin{array}{l}\text { Periodo } \\
\text { ntal } \\
\text { pocket } \\
\text { depth }\end{array}$} & No pockets & $7(=46,66 \%)$ & $5(=33,33 \%)$ \\
\hline & & $0,5-1 \mathrm{~mm}$ & $8(=53,33 \%)$ & $9(=60 \%)$ \\
\hline & & $1-1,5 \mathrm{~mm}$ & - & $1(=6,66 \%)$ \\
\hline & & $1,5-2 \mathrm{~mm}$ & - & - \\
\hline
\end{tabular}

Table 1

CONTINUATED treatment, at 2 months, 4 months and 6 months) in both groups studied, we found the following:

- The $\mathrm{OHI}$ index decreased significantly in both studied groups:

- at patient presentation, the $\mathrm{OHI}$ grade 3 index was $13.33 \%$ in both groups of patients and decreased to $0 \%$ at the last clinical examination in both patient groups;

- at the patients' presentation, none of them had the $\mathrm{OHI}$ grade 0 score in both groups of patients and the number of patients with this index increased to $66.66 \%$ at the last clinical examination in the EMF group of patients and $60 \%$ in the patients the control group;

- Dental mobility: We found that dental mobility was reduced in both groups; we mention that although initially the degree of dental mobility was the same in both groups of patients (grade I and II in percent were $46.66 \%$ ) and that the final values showed the reduction of this dental mobility in both groups of patients, however, in group I / EMF, the degree of dental mobility decreased more than in group II / control, and only teeth without pathological mobility and grade I mobility grade I were present in the EMF group). In chart2, the values of dental mobility in the two groups of patients can be compared, at presentation and in the three monitoring sessions.

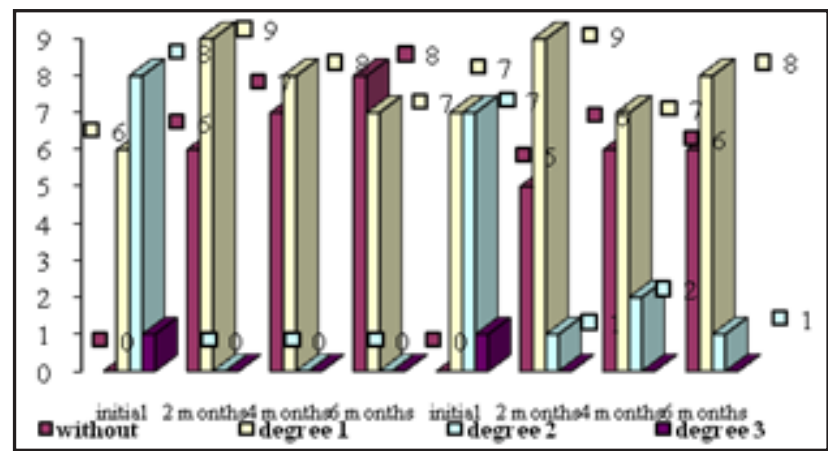

Chart 2. Dental mobility in the two groups of patients (number of patients): left - EMF group, right - control group

- Depth of periodontal pockets: was significantly reduced in both patient groups, but in group / EMF this reduction was more pronounced than in group II / control. At the end of this study, $46.66 \%$ of patients had no longer pockets in the EMF group and $33.33 \%$ in the control group, although at the first presentation all patients included in the study had gingival pockets. In chart 3 , we can see the values of the periodontal pocket depth in the two groups of patients, the presentation and the three monitoring.

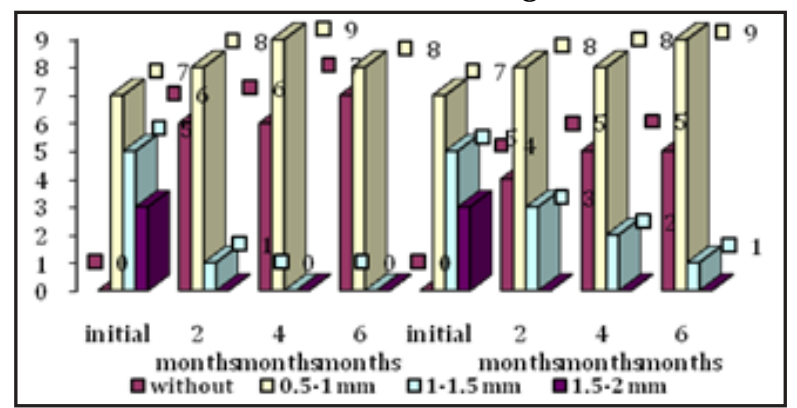

Chart 3. Depth of periodontal pockets in the two groups of patients (number of patients): left - EMC group, right - control group

In conformity with the results of study, EDSG device allows for the realization, application and maintenance of the regenerative electromagnetic field in the area of affected tissues included in the treatment.

In scientific literature, magnetic fields are used both in basic science and clinical research. They are often used to treat pain and neuro-inflammation disorders thanks to their influence on cellular responses [5].

An electromagnetic field of a certain frequency can trigger autoregeneration response in the application areas by attracting a large number of autologous undifferentiated mesenchymal cells. The proliferation of these cells in the periodontal tissues makes it possible to regenerate the bone and gum tissues, having a beneficial effect in the initial reduction and subsequently the suppression of dental mobility, gingival retraction and gingival bleeding. The research carried out by Albulescu et al. [6], which tested the use of the electromagnetic field with controlled frequency and intensity with the Electronic Doctor Stem Generator on keratinocyte cells in gingival tissue, showed a strong positive variation in cell proliferation, the maximum observed effect being $75 \%$ after 4 days exposure to fieldgenerated electromagnetic field. In this research, it is underlined that the application of low intensity and low frequency CEMs to stem cell proliferation and the differentiation in phenotypes of adipocytes and osteocytes has a beneficial and potential effect in regenerative medicine. 
The results of Ventura et al [7], demonstrated the potential use of magnetic fields for modifying the gene program of cardiac differentiation cells, without the aid of gene transfer technologies and may pave the way for novel approaches in tissue engineering and cell therapy. Zhao and Zhan [8] studied the electric fields generated by synchronized oscillations of microtubules, centrosomes and chromosomes and concluded that to characterize intracellular electric fields and to study their cellular functions further, biophysicists should develop more detailed mathematical and physical models for chromosome electric fields. After the results of Caramitu et al [9], the field of $5 \mathrm{~V} / \mathrm{cm} \& 50 \mathrm{~Hz}$ stimulates the growth of Aspergillus niger, inhibits completely those of Trichoderma viride and Aspergillus flavus. Bors et al [10], founded that the presence of the disturbing electric field of $50 \mathrm{~Hz}-6 \mathrm{Vrms} / \mathrm{cm}$, intensifies the microbiological activity, especially of Aspergillus niger, which inhibits the development of other species - including Trichoderma viride. The researches of Bunoiu etal [11], underlined that dispersing magnetic nano- microparticles in liquid polymers followed by polymerization in a mixture with a suitable catalyst, with or without a magnetic field, one obtains magnetorheological elastomers with various applications. According to the literature, electromagnetic therapy has a beneficial influence on wound healing and significantly shortens the stages of the healing process, with numerous clinical trials emphasizing the benefits of this therapy $[12,13]$. The reports by Cohen et al. [14], Gurbuz and coworkers [15], Rajaei et al. [16] and Supino et al. [17] have shown that electromagnetic field therapy does not produce genotoxic effects. Hey et al. [18] investigated the effect of Schwann cells combined with the pulsating electromagnetic field on peripheral nerve regeneration and found that retrograded marked axons and neurons increased in all treatment groups which improved peripheral nerve regeneration. According to Volponi et al. [19], dental tissue has a very limited reconstruction response, unlike stem cells in the dental pulp that are more likely to be a source of cells that facilitate regeneration, as are the stem cells of the periodontal ligament and rising roots that play more dynamic roles. The results of in vitro study effectuated by Collodel et al [20] suggested that radioelectric asymmetric conveyer technology can influence the regenerative tissue optimization treatment, which may represent a new and promising approach for the management of osteoarthritis. New discoveries in physics, biology, epigenetics, neuroscience, and psychology may foster scientists, who have so far provided a fragmented picture of the living w orld, to develop new paradigms capable to unify the various disciplines [21].

\section{Conclusions}

The occurrence of bone densification in therapy with EDSG device, observed by comparing the initial and final radiographs in all patients which consistently followed all indications, is considered to be the key beneficial element that ensures good stability of the therapeutic outcome.

EMF adjuvant therapy with EDSG device is an innovative, atraumatic and non-invasive therapy.

EMF therapyis a new therapy in dental medicine, which has not yet fully demonstrated its beneficial potential.

EMF utilisation for regenerative medicine offers new therapeutic possibilities in dentistry.

\section{References}

1.***https://ro.wikipedia.org/wiki/C\%C3\%A2mp_electromagnetic

2.HO DM-W, POPP FA, WARNKE U, Bioelectrodynamics and Biocommunication, ýTechnology \& Engineering, Utopia press, Singapore, 1994, p. 33-128

3.***https://ww w.ozassignments.com/solution/electromagneticradiation-assignment-help

4.VLADILA ,B., BECHIR, E.S., Mat. Plast., 52,no.1, 2015,, p.87-89

5.ARAGONA SE, MEREGHETTI G, LOTTI J, et al, J Biol Regul Homeost Agents. 2017 Apr-J un;31(2 Suppl. 2):219-225

6.ALBULESCU R., CODRICI E., MIHAI S., et al, FEBS J ournal. Special Issue: FEBS EMBO 2014 Conference, Paris, France, 30 August-4 September 2014. 281, Supplement s1, p. 785-808

7.VENTURA C, MAIOLI M, ASARA Y, et al. FASEB J 2005; 19: 155-157

8.ZHAO Y, ZHAN Q. Theoretical Biology \& Medical Modelling. 2012;9:26 9.CARAMITU, A., BUTOI, N., RUS, T., et al, Mat.Plast., 54 , no.2, 2017, p. $331-337$

10.BORS, A.M., BUTOI, M., CARAMITU, A.R., et al, Mat. Plast., 54, no. 3, 2017, p 447-452

11.BUNOIU, M., ANITAS, E.M., NEAMTU, J., et al, Rev. Chim. (Bucharest), 68, no. 6, 2017, p. 1205-1210

12.ZHAO LY, SONG CX, YU D, et al. Zhonghua Lao Dong Wei Sheng Zhi Ye Bing Za Zhi. 2012 Mar; 30(3):194-5

13.YE C, SUN W. Zhonghua Lao Dong Wei Sheng Zhi Ye Bing Za Zhi. 2014 Feb; 32(2):153-7

14.COHEN MM, KUNSKA A, ASTEMBORSKI JA, et al, Bioelectromag, 7 (1986) 415

15.GURBUZ N, SIRAV B, YUVACI HU, et al, Electromagn Biol Med. 2010 Aug;29(3):98-104

16.RAJAEI F, MOHAMMADIAN A. Qom University of Medical Sciences Journal, 2013, 6, 4

17.SUPINO R, BOTTONE MG, PELLICCIARI C, et al, Histol Histopathol, 2001, 16:719-726

18. HEI WH, KIM S, PARK JC, et al, Bioelectromagnetics. 2016, Mar 15. doi: 10.1002/bem.21966

19.VOLPONI AA, PANG Y, SHARPE PT, Trends Cell Biol. 2010 December; 20-206(12-6): 715-722

20.COLLODEL G, FIORAVANTI A, PASCARELLI NA, et al. Clin Interv Aging 2013; 8: 309-316

21.VENTURA C, CellR4 2014; 2 (2): e839, https://www.cellr4.org/article/ 839

Manuscript received: 08.05 .2018 